ORIGINAL ARTICLE

\section{Clinical Features and Outcomes of Takotsubo (Stress) Cardiomyopathy}

\author{
C. Templin, J.R. Ghadri, J. Diekmann, L.C. Napp, D.R. Bataiosu, M. Jaguszewski, \\ V.L. Cammann, A. Sarcon, V. Geyer, C.A. Neumann, B. Seifert, J. Hellermann, \\ M. Schwyzer, K. Eisenhardt, J. Jenewein, J. Franke, H.A. Katus, C. Burgdorf, \\ H. Schunkert, C. Moeller, H. Thiele, J. Bauersachs, C. Tschöpe, H.-P. Schultheiss, \\ C.A. Laney, L. Rajan, G. Michels, R. Pfister, C. Ukena, M. Böhm, R. Erbel, \\ A. Cuneo, K.-H. Kuck, C. Jacobshagen, G. Hasenfuss, M. Karakas, W. Koenig, \\ W. Rottbauer, S.M. Said, R.C. Braun-Dullaeus, F. Cuculi, A. Banning, T.A. Fischer, \\ T. Vasankari, K.E.J. Airaksinen, M. Fijalkowski, A. Rynkiewicz, M. Pawlak, \\ G. Opolski, R. Dworakowski, P. MacCarthy, C. Kaiser, S. Osswald, L. Galiuto, \\ F. Crea, W. Dichtl, W.M. Franz, K. Empen, S.B. Felix, C. Delmas, O. Lairez, \\ P. Erne, J.J. Bax, I. Ford, F. Ruschitzka, A. Prasad, and T.F. Lüscher
}

\section{A BSTRACT}

\section{BACKGROUND}

The natural history, management, and outcome of takotsubo (stress) cardiomyopathy are incompletely understood.

\section{METHODS}

The International Takotsubo Registry, a consortium of 26 centers in Europe and the United States, was established to investigate clinical features, prognostic predictors, and outcome of takotsubo cardiomyopathy. Patients were compared with age- and sex-matched patients who had an acute coronary syndrome.

\section{RESULTS}

Of 1750 patients with takotsubo cardiomyopathy, $89.8 \%$ were women (mean age, 66.8 years). Emotional triggers were not as common as physical triggers $(27.7 \%$ vs. $36.0 \%$, and $28.5 \%$ of patients had no evident trigger. Among patients with takotsubo cardiomyopathy, as compared with an acute coronary syndrome, rates of neurologic or psychiatric disorders were higher (55.8\% vs. $25.7 \%$ ) and the mean left ventricular ejection fraction was markedly lower $(40.7 \pm 11.2 \%$ vs. $51.5 \pm 12.3 \%)$ ( $\mathrm{P}<0.001$ for both comparisons). Rates of severe in-hospital complications including shock and death were similar in the two groups $(\mathrm{P}=0.93)$. Physical triggers, acute neurologic or psychiatric diseases, high troponin levels, and a low ejection fraction on admission were independent predictors for in-hospital complications. During long-term follow-up, the rate of major adverse cardiac and cerebrovascular events was $9.9 \%$ per patient-year, and the rate of death was $5.6 \%$ per patient-year.

\section{CONCLUSIONS}

Patients with takotsubo cardiomyopathy had a higher prevalence of neurologic or psychiatric disorders than did those with an acute coronary syndrome. This condition represents an acute heart failure syndrome with substantial morbidity and mortality. (Funded by the Mach-Gaensslen Foundation and others; ClinicalTrials .gov number, NCT01947621.)
The authors' full names, academic degrees, and affiliations are listed in the Appendix. Address reprint requests to Dr. Templin at the University Hospital Zurich, University Heart Center, Department of Cardiology, Rämistr. 100, 8091 Zurich, Switzerland, or at christian.templin@usz.ch.

Drs. Templin and Ghadri contributed equally to this article.

N Engl J Med 2015;373:929-38. DOI: 10.1056/NEJMoal406761

Copyright @ 2015 Massachusetts Medical Society. 
INCE ITS FIRST DESCRIPTION IN JAPAN in $1990,{ }^{1}$ takotsubo (stress) cardiomyopathy has gained worldwide recognition. However, after nearly 25 years of extensive efforts toward a better understanding of this disorder, current knowledge remains limited. The disease is characterized by transient systolic and diastolic left ventricular dysfunction with a variety of wall-motion abnormalities. ${ }^{2,3}$ It predominantly affects elderly women and is often preceded by an emotional or physical trigger, ${ }^{4}$ but the condition has also been reported with no evident trigger. In the acute phase, the clinical presentation, electrocardiographic findings, and biomarker profiles are often similar to those of an acute coronary syndrome. Although the cause of takotsubo cardiomyopathy remains unknown, the role of the brain-heart axis in the pathogenesis of the disease has been described.,

Takotsubo cardiomyopathy, which derives its name from the Japanese word takotsubo ("octopus pot") to describe the characteristic ballooning of the left ventricular apex, is generally recognized as a benign disorder. However, patients are at risk for recurrence even years after the first event, and data on in-hospital and longterm outcomes are limited. ${ }^{7-10}$ The potential role of catecholamine excess in the pathogenesis of takotsubo cardiomyopathy has been long debated, ${ }^{11}$ and as such beta-blockers have been proposed as a therapeutic strategy. ${ }^{12}$ Nevertheless, to our knowledge, no prospective trials evaluating the therapeutic management have been reported to date. The aim of this study was to investigate the clinical features, define prognostic predictors, and assess the clinical course and outcome of takotsubo cardiomyopathy.

\section{METHODS}

\section{STUDY POPULATION}

The International Takotsubo Registry (www .takotsubo-registry.com) was established at University Hospital Zurich in collaboration with 25 cardiovascular centers across 9 countries (Austria, Finland, France, Germany, Italy, Poland, Switzerland, the United Kingdom, and the United States) (see the Methods section in the Supplementary Appendix, available with the full text of this article at NEJM.org). Data were collected in accordance with regulations set forth by institutional review boards. From 2011 through 2014, a core team of investigators at the University Hospital Zurich reviewed the records of patients in whom takotsubo cardiomyopathy had been diagnosed between 1998 and 2014 (Fig. 1). Patients were included in the registry on the basis of the Mayo Clinic diagnostic criteria for this condition, ${ }^{13}$ as follows: the presence of a transient abnormality in left ventricular wall motion beyond a single epicardial coronary artery perfusion territory, the absence of obstructive coronary artery disease or angiographic evidence of acute plaque rupture, the presence of new electrocardiographic abnormalities or elevation in cardiac troponin levels, and the absence of pheochromocytoma and myocarditis. Exceptions to these criteria were the presence of coexisting coronary artery disease, the presence of a wall-motion abnormality that was congruent with a single coronary artery territory in a patient matching all other criteria, and death during the acute phase before wallmotion recovery.

When eligibility for inclusion was uncertain, cases were reviewed by all members of the core team of investigators to reach consensus. Standardized forms were used to collect patient data, including baseline characteristics, triggering factors (categorized as emotional or physical) (Fig. S2 in the Supplementary Appendix) ${ }^{9}$, cardiovascular risk factors, coexisting illnesses, results on electrocardiography and echocardiography, laboratory values, results on coronary angiography, use of medications, and use of critical care. Takotsubo cardiomyopathy was classified as apical, midventricular, basal, or focal (see the Methods section in the Supplementary Appendix).

\section{COMPARISON OF TAKOTSUBO CARDIOMYOPATHY AND ACUTE CORONARY SYNDROME}

We compared a subgroup of 455 patients in whom takotsubo cardiomyopathy had been diagnosed with 455 age- and sex-matched patients with an acute coronary syndrome who either fulfilled the third universal definition of myocardial infarction $^{14}$ or had unstable angina caused by obstructive coronary artery disease. Data for patients with takotsubo cardiomyopathy were collected from five dedicated study centers (see the Methods section in the Supplementary Appendix), and data for patients with an acute coronary syndrome were collected from the Zurich Acute Coronary Syndrome Registry, since these centers had the most comprehensive patient 


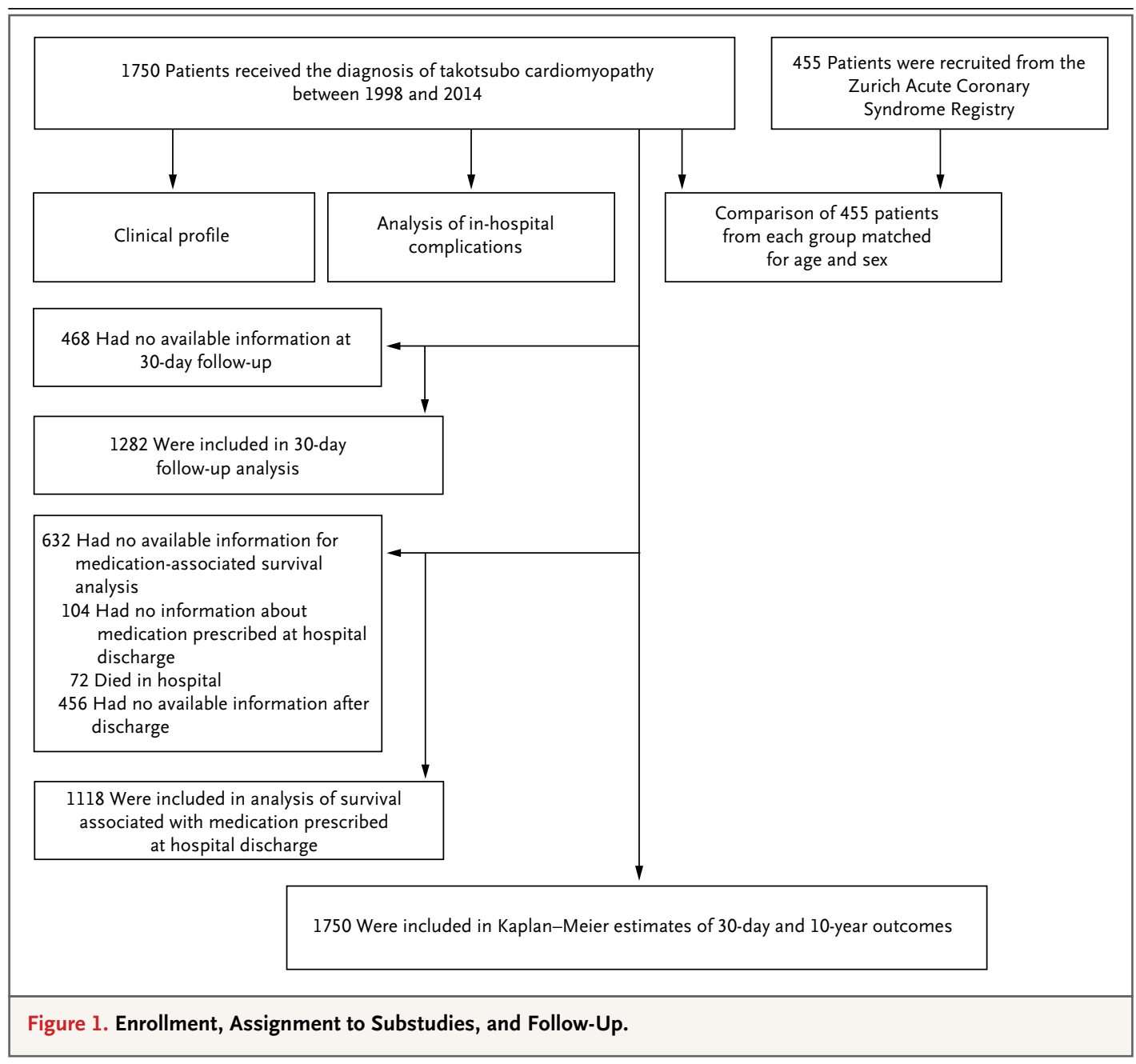

records, including neurologic and psychiatric diagnoses according to the Diagnostic and Statistical Manual of Mental Disorders, fourth edition. ${ }^{15}$

\section{OUTCOMES}

We recorded all in-hospital complications, including catecholamine use, cardiogenic shock, the use of invasive or noninvasive ventilation or cardiopulmonary resuscitation, and death from any cause. Follow-up analysis included death from any cause and major adverse cardiac and cerebrovascular events (a composite of a recurrence of takotsubo cardiomyopathy, myocardial infarction, stroke or transient ischemic attack, or death from any cause). Follow-up data obtained by core team members were based on clinical visits, medical records, or telephone interviews. In cases in which the native language of the patients did not allow for follow-up by core team members (e.g., in Finland and Italy), follow-up was obtained by local investigators on the basis of a dedicated case-report form. Oneyear mortality was analyzed in subgroups of patients who were defined according to the use of angiotensin-converting-enzyme inhibitors, angiotensin-receptor blockers, or beta-blockers as the discharge medication.

\section{STATISTICAL ANALYSIS}

Continuous variables are presented as means and standard deviations or medians and interquartile ranges. Categorical variables are provided with percentages. We used the Wilcoxon ranksum test to compare continuous variables and the Pearson chi-square test or Fisher's exact test to compare categorical variables. For analysis of recovery of the left ventricular ejection fraction, one-way analysis of variance was performed. 
A two-sided $\mathrm{P}$ value of less than 0.05 was considered to indicate statistical significance.

A chi-square analysis was performed to identify univariate predictors for in-hospital complications. Variables that were significant in univariate analysis were included in a multiple logistic-regression analysis to search for independent predictors. Model calibration was assessed with the use of the Hosmer-Lemeshow test. Odds ratios are reported with $95 \%$ confidence intervals.

We used the Kaplan-Meier method to provide survival estimates, which were assessed with a log-rank test. For survival related to discharge medication, two independent propensity scores were computed for the use of beta-blockers and angiotensin-converting-enzyme inhibitors or angiotensin-receptor blockers to limit the influence of potential confounding variables. For computation of the propensity scores, a nonparsimonious regression with the medication as a dependent variable and potential confounding covariates (age, sex, hypertension, diabetes mellitus, left ventricular ejection fraction, heart rate, use of calcium-channel antagonists, and coronary artery disease) were included. Missing values were replaced by multiple regression imputation. We used the Hosmer-Lemeshow test to evaluate the validity of logistic regression. Oneyear survival after discharge was assessed by means of the log-rank test and Cox regression with adjustment for the propensity score for medication use on a logit scale.

The proportional-hazards assumption was verified by means of plotting the Schoenfeld residuals with Stata software, version 13.1 (StataCorp). All analyses were performed with the use of SPSS statistical software, versions 21.0 and 22.0 (IBM). All graphs were compiled with the use of Prism 6 software (GraphPad).

\section{RESULTS}

\section{STUDY PATIENTS}

Of the 1750 patients with takotsubo cardiomyopathy, $1571(89.8 \%)$ were women (mean $[ \pm S D]$ age, $66.8 \pm 13.0$ years), and 1384 of all patients $(79.1 \%)$ were women older than 50 years of age (Table 1, and Tables S1 and S2 and Fig. S1 in the Supplementary Appendix). The predominant symptom on admission was chest pain (75.9\%), followed by dyspnea (46.9\%) and syncope (7.7\%). Physical triggers were more frequently present than emotional triggers (36.0\% vs. $27.7 \%$ ), whereas $7.8 \%$ of patients had both triggers. In $28.5 \%$ of patients, takotsubo cardiomyopathy occurred without any evident trigger. Emotional triggers were more common among women, whereas physical triggers were more prevalent among men (Table 1, and Tables S1 and S2 and Fig. S2 in the Supplementary Appendix).

Apical takotsubo cardiomyopathy was identified in $81.7 \%$ of patients, whereas the midventricular form was found in $14.6 \%$, and basal and focal forms were diagnosed in $2.2 \%$ and $1.5 \%$, respectively (Fig. 2, Tables S1 and S2 in the Supplementary Appendix, and Videos 1 through 4).

On admission, troponin levels were elevated in $87.0 \%$ of patients, with mean levels similar to those in patients with an acute coronary syndrome. Although troponin levels increased by as much as a factor of 1.8 during hospitalization among patients with takotsubo cardiomyopathy, patients with an acute coronary syndrome had an increase by a factor of 6 over the admission value $(\mathrm{P}<0.001)$. Creatine kinase was not substantially elevated in the majority of patients with takotsubo cardiomyopathy (mean level, factor of 0.87 of the upper limit of the normal range). A total of $82.9 \%$ of the patients had elevated levels of brain natriuretic peptide on admission (by a factor of 5.9 of the upper limit of the normal range), which significantly exceeded the levels among the patients with an acute coronary syndrome (Table 1 , and Tables $\mathrm{S} 1$ and S2 in the Supplementary Appendix).

Results on electrocardiography on admission showed sinus rhythm in more than $90 \%$ of the patients with takotsubo cardiomyopathy, who had a significantly higher heart rate than patients with an acute coronary syndrome. The rates of ST-segment elevation were similar in the two groups. In contrast, ST-segment depression occurred in only $8.3 \%$ of patients with takotsubo cardiomyopathy but in $31.1 \%$ of those with an acute coronary syndrome. Notably, a prolongation in the QT interval corrected for heart rate was detectable in a substantial proportion of patients with takotsubo cardiomyopathy (Table 1 , and Tables S1 and S2 in the Supplementary Appendix).

A reduced left ventricular ejection fraction (mean value, $40.7 \pm 11.2 \%$ ) was noted in $86.5 \%$ of patients with takotsubo cardiomyopathy on admission but in only $54.2 \%$ of patients with an acute coronary syndrome (mean value, $51.5 \pm 12.3 \% ; \mathrm{P}<0.001)$. Of note, $93.0 \%$ of patients 


\begin{tabular}{|c|c|c|c|c|}
\hline \multirow[t]{2}{*}{ Characteristic } & \multicolumn{2}{|c|}{ Takotsubo Cardiomyopathy } & \multirow{2}{*}{$\begin{array}{l}\text { Acute Coronary Syndrome } \\
\text { Matched Cohort } \\
(\mathrm{N}=455)\end{array}$} & \multirow[t]{2}{*}{ P Value } \\
\hline & $\begin{array}{l}\text { Total Cohort } \\
(\mathrm{N}=1750)\end{array}$ & $\begin{array}{l}\text { Matched Cohort } \\
\qquad(\mathrm{N}=455)\end{array}$ & & \\
\hline Female sex - no. (\%) & $1571(89.8)$ & $411(90.3)$ & $411(90.3)$ & 1.00 \\
\hline Age $-y r$ & $66.4 \pm 13.1$ & $67.7 \pm 12.5$ & $68.7 \pm 12.3$ & 0.19 \\
\hline Chest pain — no./total no. (\%) & $1229 / 1619(75.9)$ & $322 / 438(73.5)$ & $361 / 403(89.6)$ & $<0.001$ \\
\hline Dyspnea — no./total no. (\%) & $760 / 1620(46.9)$ & $208 / 439(47.4)$ & $128 / 363(35.3)$ & 0.001 \\
\hline Median troponin $(\mathrm{IQR})-$ factor $\times \mathrm{ULN}$ & $7.70(2.22-24.00)$ & $7.68(2.38-24.21)$ & $8.30(1.80-36.40)$ & 0.62 \\
\hline Median creatine kinase $(\mathrm{IQR})-$ factor $\times$ ULN & $0.85(0.52-1.48)$ & $0.87(0.55-1.42)$ & $1.12(0.60-2.97)$ & $<0.001$ \\
\hline $\begin{array}{l}\text { Median brain natriuretic peptide (IQR) - } \\
\text { factor } \times \text { ULN } \mathbb{S}\end{array}$ & $6.12(2.12-15.70)$ & $5.89(1.68-13.92)$ & $2.91(0.88-8.26)$ & $<0.001$ \\
\hline \multicolumn{5}{|l|}{ ST-segment change - no./total no. (\%) } \\
\hline Elevation & $690 / 1578(43.7)$ & $185 / 420(44.0)$ & $233 / 455(51.2)$ & 0.03 \\
\hline Depression & $121 / 1578(7.7)$ & $35 / 420(8.3)$ & $122 / 392(31.1)$ & $<0.001$ \\
\hline Heart rate - beats $/ \mathrm{min}$ & $87.5 \pm 21.8$ & $87.3 \pm 21.8$ & $76.1 \pm 18.3$ & $<0.001$ \\
\hline Systolic blood pressure $-\mathrm{mm} \mathrm{Hg}$ & $130.6 \pm 28.8$ & $131.6 \pm 31.4$ & $131.5 \pm 28.2$ & 0.96 \\
\hline Left ventricular ejection fraction — \% & $41.1 \pm 11.8$ & $40.7 \pm 11.2$ & $51.5 \pm 12.3$ & $<0.001$ \\
\hline $\begin{array}{l}\text { Left ventricular end diastolic pressure - } \\
\qquad \mathrm{mm} \mathrm{Hg}\end{array}$ & $21.3 \pm 8.0$ & $22.1 \pm 7.7$ & $20.1 \pm 7.8$ & 0.001 \\
\hline \multicolumn{5}{|l|}{$\begin{array}{l}\text { Coexisting medical condition - no./ } \\
\text { total no. (\%) }\end{array}$} \\
\hline Coronary artery disease & 245/1597 (15.3) & $96 / 455(21.1)$ & $455 / 455(100.0)$ & $<0.001$ \\
\hline Neurologic or psychiatric disorder $\|$ & $714 / 1525(46.8)$ & $252 / 452(55.8)$ & $115 / 448(25.7)$ & $<0.001$ \\
\hline Acute neurologic disorder & $143 / 1528(9.4)$ & $41 / 452(9.1)$ & $4 / 448(0.9)$ & $<0.001$ \\
\hline Past or chronic neurologic disorder & $293 / 1512(19.4)$ & $98 / 452(21.7)$ & $62 / 448(13.8)$ & 0.002 \\
\hline Acute psychiatric disorder & $149 / 1525(9.8)$ & $57 / 452(1.3)$ & $6 / 448(1.3)$ & $<0.001$ \\
\hline Past or chronic psychiatric disorder & $444 / 1512(29.4)$ & $165 / 451(36.6)$ & $61 / 448(13.6)$ & $<0.001$ \\
\hline \multicolumn{5}{|l|}{ Treatment — no./total no. (\%) } \\
\hline Catecholamine & $212 / 1735(12.2)$ & $53 / 455(11.6)$ & $50 / 455(11.0)$ & 0.75 \\
\hline Invasive or noninvasive ventilation & $301 / 1735(17.3)$ & $63 / 455(13.8)$ & $41 / 455(9.0)$ & 0.02 \\
\hline Cardiopulmonary resuscitation & $149 / 1735(8.6)$ & $40 / 455(8.8)$ & $53 / 455(11.6)$ & 0.16 \\
\hline \multicolumn{5}{|l|}{ In-hospital outcomes - no./total no. (\%) } \\
\hline Cardiogenic shock & $170 / 1716(9.9)$ & $55 / 445(12.4)$ & $48 / 455(10.5)$ & 0.39 \\
\hline Death & $72 / 1750(4.1)$ & $17 / 455(3.7)$ & $24 / 455(5.3)$ & 0.26 \\
\hline \multicolumn{5}{|c|}{$\begin{array}{l}\text { Plus-minus values are means } \pm \text { SD. Full details regarding characteristics of patients are provided in Table S2 in the Supplementary Appendix. } \\
\text { ULN denotes upper limit of the normal range. } \\
\text { Means in the matched cohorts were compared with the Wilcoxon rank-sum test, and proportions were compared with the Pearson chi- } \\
\text { square test. } \\
\text { Included in this category are the upper limits of the normal range for troponin T, high-sensitivity troponin T, and troponin I. } \\
\text { Included in this category are the upper limits of the normal range for brain natriuretic peptide and the N-terminal of prohormone brain } \\
\text { natriuretic peptide. } \\
\text { Data regarding the left ventricular ejection fraction were obtained either during catheterization or echocardiography. If both results were } \\
\text { available, data that were obtained during catheterization were used. } \\
\text { Patients could have an acute disorder as well as a past or chronic disorder. }\end{array}$} \\
\hline
\end{tabular}

with takotsubo cardiomyopathy had an increased On coronary angiography, coronary artery disleft ventricular end-diastolic pressure $(>11 \mathrm{~mm} \mathrm{Hg})$ ease was diagnosed in $15.3 \%$ of patients with on angiography (Table 1, and Tables S1 and S2 takotsubo cardiomyopathy. On admission, 32.5\% and Fig. S3 in the Supplementary Appendix). of the patients were taking beta-blockers, and 


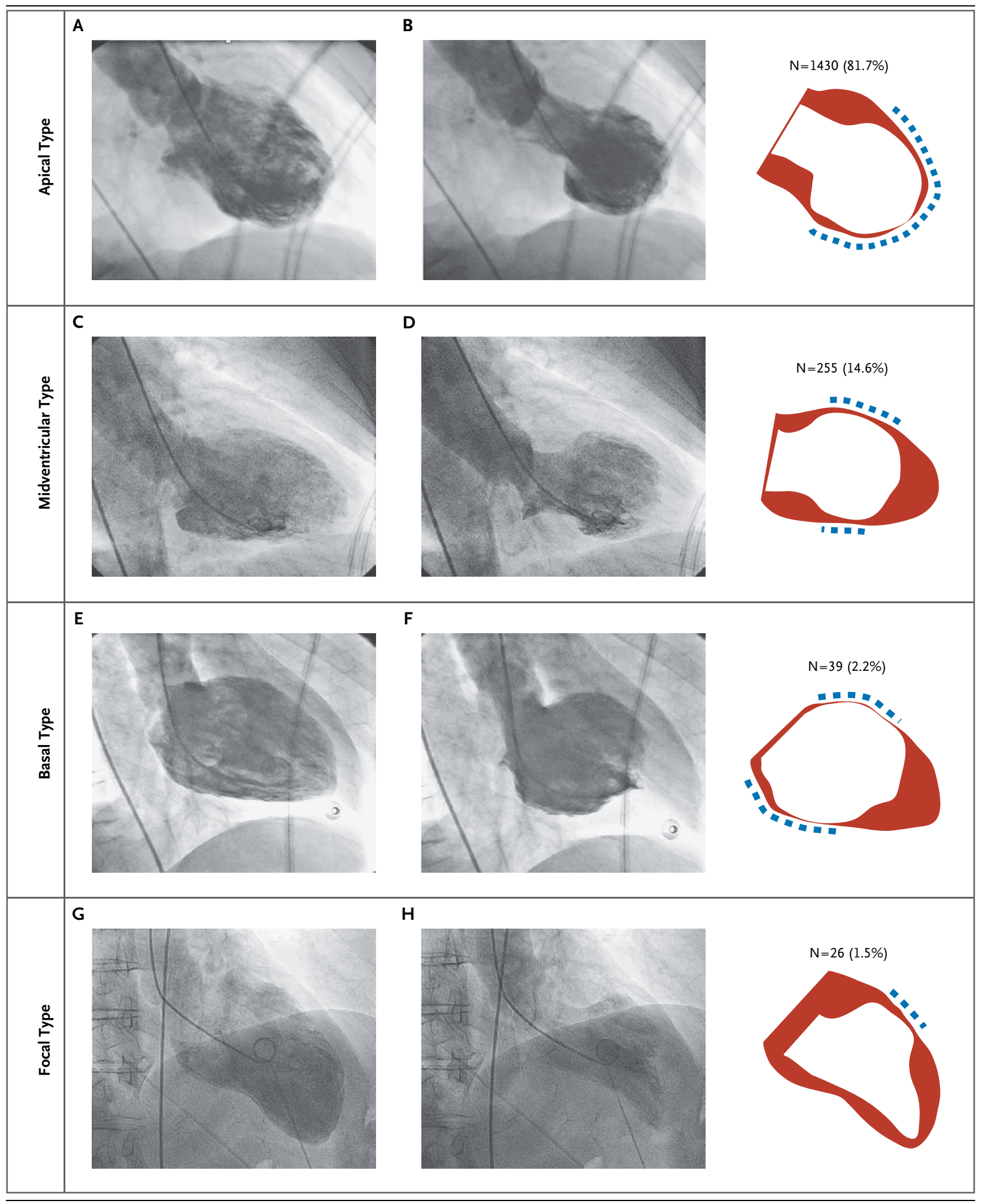


Figure 2 (facing page). Four Types of Takotsubo Cardiomyopathy.

Among the 1750 study patients, the most common type of takotsubo (stress) cardiomyopathy was the apical type (in $81.7 \%$ of patients) (Panels A and B), followed by the midventricular type (in 14.6\% of patients) (Panels $C$ and D), the basal type (in $2.2 \%$ of patients) (Panels $E$ and F), and the focal type (in $1.5 \%$ of patients) (Panels $\mathrm{G}$ and $\mathrm{H}$ ). All left ventricular angiograms were obtained in the right anterior oblique view (30 degrees) during diastole (left column) and systole (middle column). In the far right column, the wall-motion abnormality that was observed with each type of the disorder is shown, with red indicating diastole, white indicating systole, and the dashed line indicating the location of the wall-motion abnormality.

$37.9 \%$ were taking either angiotensin-convertingenzyme inhibitors or angiotensin-receptor blockers, rates of use that increased at discharge (to $78.1 \%$ and $79.3 \%$, respectively) (Table 1 , and Tables S1 and S2 in the Supplementary Appendix).

More than half the patients with takotsubo cardiomyopathy $(55.8 \%)$ had a history or an acute episode of a neurologic or psychiatric disorder, conditions that were evident in only $25.7 \%$ of patients with an acute coronary syndrome ( $\mathrm{P}<0.001)$. Specifically, although $27.0 \%$ of patients with takotsubo cardiomyopathy had an acute, former, or chronic history of a neurologic disorder, $42.3 \%$ had received a diagnosis of a psychiatric illness, with half of such illnesses identified as affective disorders (Fig. S4 in the Supplementary Appendix). The high prevalence of neurologic and psychiatric disorders was also reflected by the fact that a substantial number of patients were taking one or more antidepressants $(17.1 \%)$; most of these medications were selective serotonin-reuptake inhibitors or benzodiazepines (Table 1, and Table S2 in the Supplementary Appendix).

\section{CLINICAL COURSE}

Serial echocardiographic assessments of patients with takotsubo cardiomyopathy revealed remarkable recovery of systolic left ventricular function over time (Fig. S3 in the Supplementary Appendix). However, $21.8 \%$ of patients had a combined end point of serious in-hospital complications, with rates equal to or higher than those of patients with an acute coronary syndrome (Table S2 and Fig. S5 in the Supplementary Appendix). Most of these end points, including in-hospital death, occurred more frequently among men than among women (Table S1 in the Supplementary Appendix). Furthermore, patients with takotsubo cardiomyopathy had some severe complications, including ventricular tachycardia $(3.0 \%)$, ventricular thrombus $(1.3 \%)$, and ventricular rupture $(0.2 \%)$.

The type of takotsubo cardiomyopathy and the coexistence of coronary artery disease were not related to the incidence of in-hospital complications, as shown on univariate analysis. Multivariate analysis revealed that older age and the presence of emotional triggers independently predicted a lower incidence of the combined end point. In contrast, the presence of physical triggers, acute neurologic or psychiatric disease, a first troponin measurement of more than 10 times the upper limit of the normal level, and a left ventricular ejection fraction of less than $45 \%$ each predicted a higher incidence of the combined end point (Fig. S5 in the Supplementary Appendix).

During the first 30 days after admission, the rate of major adverse cardiac and cerebrovascular events was $7.1 \%$, which included death and stroke or transient ischemic attack as the most frequent events (Table S1 and Fig. S6 in the Supplementary Appendix). Again, men were at higher risk for major adverse cardiac and cerebrovascular events than women $(13.7 \%$ vs. $6.3 \%$, $\mathrm{P}=0.002)$.

\section{LONG-TERM OUTCOMES}

Long-term follow-up of patients with takotsubo cardiomyopathy revealed a rate of death from any cause of 5.6\% per patient-year and a rate of major adverse cardiac and cerebrovascular events of $9.9 \%$ per patient-year. Among these patients, the incidence of myocardial infarction was relatively low, given that the rate of stroke or transient ischemic attack was $1.7 \%$ per patient-year and the rate of recurrence of takotsubo cardiomyopathy was $1.8 \%$ per patient-year, with a span of 25 days up to 9.2 years after the first event (Fig. 3, and Table S1 in the Supplementary Appendix). Of note, men had increased rates of death from any cause $(12.9 \%$ vs. $5.0 \%$ per patient-year, $\mathrm{P}<0.001)$ and major adverse cardiac and cerebrovascular events $(16.0 \%$ vs. $8.7 \%$ per patient-year, $\mathrm{P}=0.002$ ) during long-term followup (Table $S 1$ in the Supplementary Appendix).

In view of the paucity of data regarding ther- 


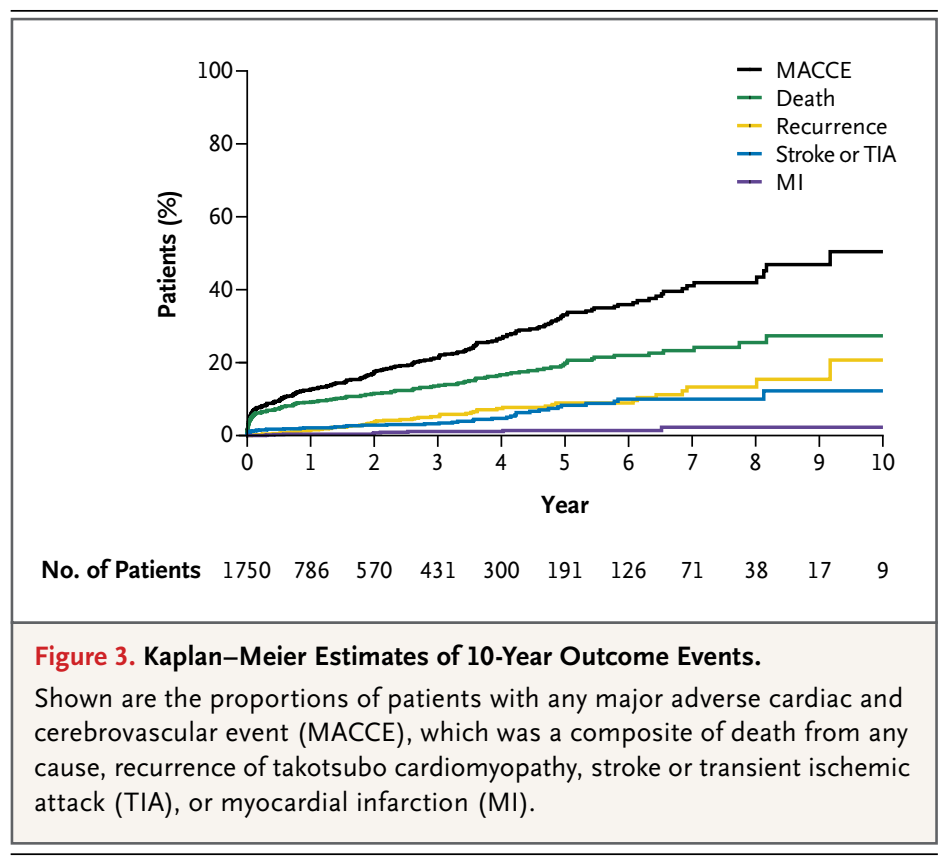

apy among these patients, we performed a retrospective analysis of outcome in relation to the medication that had been prescribed at the time of hospital discharge, including a propensityscore analysis to compensate for potential indication bias. The use of angiotensin-convertingenzyme inhibitors or angiotensin-receptor blockers was associated with improved survival at 1 year $(\mathrm{P}=0.001$ by the log-rank test and after adjustment for the propensity score). In contrast, at 1 year, there was no evidence of any survival benefit for the use of beta-blockers $(\mathrm{P}=0.53$ by the log-rank test; $\mathrm{P}=0.72$ after adjustment for the propensity score) (Table S3 and Fig. S7 in the Supplementary Appendix).

\section{DISCUSSION}

Our study demonstrates that takotsubo (stress) cardiomyopathy represents an acute heart failure syndrome that is associated with a substantial risk for adverse events. The uneven sex distribution among the patients with takotsubo cardiomyopathy that we observed (female-to-male ratio, 9:1) is in line with most previous reports from Western countries. ${ }^{9,16}$ In Japan, takotsubo cardiomyopathy is more prevalent among men, ${ }^{17}$ for unclear reasons.

Previous studies have suggested that takotsubo cardiomyopathy is predominantly preceded by emotional triggers. ${ }^{11,18}$ Subsequent studies have indicated that the disease may also occur with physical triggers or even without any evident preceding trigger.9,19 Our data reveal that the prevalence of physical triggers exceeds that of emotional triggers and that the absence of a trigger does not preclude a diagnosis of this disorder.

More than half of all patients with takotsubo cardiomyopathy had an acute, former, or chronic neurologic or psychiatric disorder. This finding corroborates and expands findings of previous reports involving patients with takotsubo cardiomyopathy in the context of subarachnoid hemorrhage, ${ }^{20}$ epilepsy, ${ }^{21}$ electroconvulsive therapy, ${ }^{22}$ head injury, ${ }^{23}$ stroke, ${ }^{24}$ and anxiety or depression. ${ }^{25}$ Of note, the coronary microcirculation is innervated by neurons that originate in the brain stem and mediate vasoconstriction, which supports the concept that myocardial stunning due to microvascular dysfunction among patients with takotsubo cardiomyopathy ${ }^{26}$ may be of neurogenic origin. ${ }^{27}$ Consistently, histopathological findings in cardiac tissue samples obtained from patients with sudden unexpected death during epilepsy or subarachnoid hemorrhage strongly resembled those of patients who died during an episode of takotsubo cardiomyopathy. ${ }^{5,28}$ Patients with takotsubo cardiomyopathy are more likely to present with neurologic and psychiatric disorders than are patients with an acute coronary syndrome. This finding suggests a potential link between neuropsychiatric disorders and takotsubo cardiomyopathy and should prompt prospective studies.

Since patients with takotsubo cardiomyopathy commonly present with symptoms similar to those among patients with an acute coronary syndrome, ${ }^{13}$ initial diagnosis and treatment of patients in the emergency room remains challenging. Our study confirms that troponin levels and electrocardiographic changes on admission are not sufficient to differentiate between these two disorders, ${ }^{9}$ since more than $80 \%$ of patients with takotsubo cardiomyopathy had elevated troponin levels and nearly $80 \%$ had signs of myocardial ischemia on initial electrocardiography. Therefore, early coronary angiography remains necessary to rule out an acute coronary syndrome. Notably, $15.3 \%$ of patients with takotsubo cardiomyopathy had evidence of coexisting coronary artery disease on angiography. This finding shows that the presence of coronary artery disease is not an exclusion criterion for the diagnosis of takotsubo cardiomyopathy. ${ }^{13,29}$ 
Takotsubo cardiomyopathy should be considered to be an acute heart failure syndrome, as reflected by the markedly increased levels of brain natriuretic peptide and left ventricular end-diastolic pressure. Consistently, systolic left ventricular function was reduced to an even greater extent among patients with takotsubo cardiomyopathy than among those with an acute coronary syndrome. In parallel, nearly one fifth of all patients with takotsubo cardiomyopathy in our study had serious in-hospital complications, a proportion that was similar to that of age- and sex-matched patients with an acute coronary syndrome. This finding illustrates the previously underestimated risk of complications during the acute phase of the disease and highlights the need for concise clinical evaluation, monitoring, and management. We identified six measurements for predicting the risk of complications in the acute phase. Although elderly patients with emotional triggers were at lower risk, younger patients with physical triggers and acute neurologic or psychiatric diseases had an increased incidence of acute complications. Thus, our data show that the spectrum of takotsubo cardiomyopathy is wide and ranges from low to very high risk in the acute phase. The relatively rapid recovery of left ventricular function and a selection bias of previous reports toward low-risk patients generated the misapprehension that this condition is a universally benign disease.

Furthermore, patients had substantial rates of death and complications after the acute phase of the disease, with a rate of death per patientyear of $5.6 \%$ and a rate of stroke or transient ischemic attack of $1.7 \%$ per patient-year. Thus, it is of special interest whether medical treatment influences the outcome after the acute phase of takotsubo cardiomyopathy. The use of angiotensin-converting-enzyme inhibitors or angiotensinreceptor blockers, but not of beta-blockers, was associated with improved survival. Although it has been proposed that beta-blockers might prevent takotsubo cardiomyopathy events, ${ }^{12}$ the condition developed in $32.5 \%$ of the patients in our study while they were taking these agents. Of 57 patients with recurrent takotsubo cardiomyopathy, 29 were taking beta-blockers at the time of the second event. These data suggest that betablockers are not effective in preventing takotsubo cardiomyopathy. Notwithstanding, these findings should be considered solely as hypothesis generating owing to the observational nature of the study.

Supported by research grants from the Mach-Gaensslen Foundation, Prof. Otto Beisheim Foundation, and Swiss Heart Foundation (to Dr. Templin), the Olten Heart Foundation (to Drs. Templin and Ghadri), the University of Zurich (to Dr. Ghadri), the Swiss National Science Foundation, and the Foundation for Cardiovascular Research-Zurich Heart House.

Dr. Templin reports receiving fees for serving on advisory boards from Abbott Vascular and Boston Scientific, fees for training in transcatheter aortic-valve implantation from Boston Scientific, Edwards Lifesciences, and Medtronic, travel support from Abbott Vascular, Boston Scientific, Biosensors, Edwards Lifesciences, and Medtronic, and grant support from Abbott Vascular and Biosensors; Dr. Napp, receiving travel support from Biotronik, Abbott, Eli Lilly, Servier, Volcano, Boston Scientific, and Pfizer and attending a seminar organized by Medtronic; Dr. Kuck, receiving lecture fees and grant support from St. Jude Medical, Biosense Webster, and Medtronic; and Dr. Lüscher, receiving fees for serving on advisory boards from AstraZeneca and grant support from AstraZeneca, Eli Lilly, and Medtronic. No other potential conflict of interest relevant to this article was reported.

Disclosure forms provided by the authors are available with the full text of this article at NEJM.org.

APPENDIX

The authors' full names and academic degrees are as follows: Christian Templin, M.D., Ph.D., Jelena R. Ghadri, M.D., Johanna Diekmann, L. Christian Napp, M.D., Dana R. Bataiosu, M.D., Milosz Jaguszewski, M.D., Victoria L. Cammann, Annahita Sarcon, M.D., Verena Geyer, Catharina A. Neumann, Burkhardt Seifert, Ph.D., Jens Hellermann, M.D., Moritz Schwyzer, M.D., Katharina Eisenhardt, M.D., Josef Jenewein, M.D., Jennifer Franke, M.D., Hugo A. Katus, M.D., Christof Burgdorf, M.D., Heribert Schunkert, M.D., Christian Moeller, M.D., Holger Thiele, M.D., Johann Bauersachs, M.D., Carsten Tschöpe, M.D., Heinz-Peter Schultheiss, M.D., Charles A. Laney, M.D., Lawrence Rajan, M.D., Guido Michels, M.D., Roman Pfister, M.D., Christian Ukena, M.D., Michael Böhm, M.D., Raimund Erbel, M.D., Alessandro Cuneo, M.D., Karl-Heinz Kuck, M.D., Claudius Jacobshagen, M.D., Gerd Hasenfuss, M.D., Mahir Karakas, M.D., Wolfgang Koenig, M.D., Wolfgang Rottbauer, M.D., Samir M. Said, M.D., Ruediger C. Braun-Dullaeus, M.D., Florim Cuculi, M.D., Adrian Banning, M.D., Thomas A. Fischer, M.D., Tuija Vasankari, M.D., K.E. Juhani Airaksinen, M.D., Marcin Fijalkowski, M.D., Andrzej Rynkiewicz, M.D., Maciej Pawlak, M.D., Grzegorz Opolski, M.D., Rafal Dworakowski, M.D., Philip MacCarthy, M.D., Ph.D., Christoph Kaiser, M.D., Stefan Osswald, M.D., Leonarda Galiuto, M.D., Filippo Crea, M.D., Wolfgang Dichtl, M.D., Ph.D., Wolfgang M. Franz, M.D., Klaus Empen, M.D., Stephan B. Felix, M.D., Clément Delmas, M.D., Olivier Lairez, M.D., Ph.D., Paul Erne, M.D., Jeroen J. Bax, M.D., Ph.D., Ian Ford, Ph.D., Frank Ruschitzka, M.D., Abhiram Prasad, M.D., and Thomas F. Lüscher, M.D.

The authors' affiliations are as follows: University Heart Center, Department of Cardiology (C. Templin, J.R.G., J.D., D.R.B., M.J., V.L.C., V.G., C.A.N., M.S., P.E., F.R., T.F.L.), and Department of Psychiatry and Psychotherapy (K. Eisenhardt, J.J.), University Hospital Zurich, and Division of Biostatistics, Epidemiology, Biostatistics, and Prevention Institute, University of Zurich (B.S.), Zurich, Spitalregion Rheintal Werdenberg Sarganserland, Altstätten (J.H.), Department of Cardiology, Kantonsspital Lucerne, Lucerne (F. Cuculi, P.E.), Department of Cardiology, Kantonsspital Winterthur, Winterthur (T.A.F.), and Department of Cardiology, University Hospital Basel, Basel (C.K., S.O.) — all in Switzerland; Department of Cardiology and Angiology, Hannover Medical School, Hannover (L.C.N., J.B.), Department of Cardiology, Heidelberg University Hospital, Heidelberg (J.F., H.A.K.), Deutsches Herzzentrum München, Tech- 
nische Universität München (C.B., H.S., W.K.), and DZHK (German Center for Cardiovascular Research), partner site Munich Heart Alliance (H.S., W.K.), Munich, University Heart Center Lübeck, Medical Clinic II, Department of Cardiology, Angiology and Intensive Care Medicine, Lübeck (C.M., H.T.), DZHK, partner site Hamburg/Kiel/Lübeck (C.M., H.T., M.K.), Division of Cardiology, Asklepios Clinics St. Georg Hospital (A.C., K.-H.K.), and Department of General and Interventional Cardiology, University Heart Center Hamburg (M.K.), Hamburg, Department of Cardiology, Charité, Campus Rudolf Virchow, Berlin (C. Tschöpe, H.-P.S.), Department of Internal Medicine III, Heart Center University of Cologne, Cologne (G.M., R.P.), Department of Internal Medicine III, Cardiology, Angiology, and Intensive Care Medicine, Saarland University, Homburg (C.U., M.B.), Department of Cardiology, University Hospital Essen, Essen (R.E.), Clinic for Cardiology and Pneumology, Georg August University Göttingen (C.J., G.H.), and DZHK, partner site Göttingen (C.J., G.H.), Göttingen, Department of Internal Medicine II-Cardiology, University of Ulm, Medical Center, Ulm (M.K., W.K., W.R.), Internal Medicine/Cardiology, Angiology, and Pneumology, Magdeburg University, Magdeburg (S.M.S., R.C.B.-D.), University Medicine Greifswald, Department of Internal Medicine B, Greifswald (K. Empen, S.B.F.), and DZHK, partner site Greifswald, Greifswald (K. Empen, S.B.F.) - all in Germany; University of California Davis Medical Center, Davis (A.S.); Division of Cardiovascular Medicine, Gill Heart Institute, University of Kentucky, Lexington (C.A.L., L.R.); Department of Cardiology, John Radcliffe Hospital, Oxford University Hospitals, Oxford (F. Cuculi, A.B.), Department of Cardiology, Kings College Hospital, Kings Health Partners (R.D., P.M.), and Cardiac Centre, St. George's, University of London (A.P.), London, and Robertson Center for Biostatistics, University of Glasgow, Glasgow (I.F.) - all in the United Kingdom; Heart Center, Turku University Hospital and University of Turku, Turku, Finland (T.V., K.E.J.A.); First Department of Cardiology, Medical University of Gdansk, Gdansk (M.F.), Department of Cardiology and Cardiosurgery, University of Warmia and Mazury, Olsztyn (A.R.), and Department of Cardiology, Medical University of Warsaw, Warsaw (M.P., G.O.) - all in Poland; Department of Cardiovascular Sciences, Catholic University of the Sacred Heart Rome, Rome (L.G., F. Crea); University Hospital for Internal Medicine III (Cardiology and Angiology), Medical University Innsbruck, Innsbruck, Austria (W.D., W.M.F.); Department of Cardiology and Cardiac Imaging Center, University Hospital of Rangueil, Toulouse, France (C.D., O.L.); Department of Cardiology, Leiden University Medical Center, Leiden, the Netherlands (J.J.B.); and Division of Cardiovascular Diseases, Mayo Clinic, Rochester, MN (A.P.).

REFERENCES

1. Sato HTH, Uchida T, Dote K, Ishihara M. Tako-tsubo-like left ventricular dysfunction due to multivessel coronary spasm. In: Kodama K, Haze K, Hori M, eds. Clinical aspect of myocardial injury: from ischemia to heart failure. Tokyo: Kagakuhyoronsha Publishing, 1990:56-64. (In Japanese.)

2. Hurst RT, Prasad A, Askew JW III, Sengupta PP, Tajik AJ. Takotsubo cardiomyopathy: a unique cardiomyopathy with variable ventricular morphology. JACC Cardiovasc Imaging 2010;3:641-9.

3. Medeiros K, O'Connor MJ, Baicu CF, et al. Systolic and diastolic mechanics in stress cardiomyopathy. Circulation 2014; 129:1659-67.

4. Tsuchihashi $\mathrm{K}$, Ueshima K, Uchida T, et al. Transient left ventricular apical ballooning without coronary artery stenosis: a novel heart syndrome mimicking acute myocardial infarction: angina pectorismyocardial infarction investigations in Japan. J Am Coll Cardiol 2001;38:11-8.

5. Samuels MA. The brain-heart connection. Circulation 2007;116:77-84.

6. Suzuki H, Matsumoto Y, Kaneta T, et al. Evidence for brain activation in patients with takotsubo cardiomyopathy. Circ J 2014;78:256-8.

7. Citro R, Rigo F, D'Andrea A, et al. Echocardiographic correlates of acute heart failure, cardiogenic shock, and inhospital mortality in tako-tsubo cardiomyopathy. JACC Cardiovasc Imaging 2014; 7:119-29.

8. Previtali M, Repetto A, Camporotondo $\mathrm{R}$, et al. Clinical characteristics and outcome of left ventricular ballooning syndrome in a European population. Am J Cardiol 2011;107:120-5.

9. Sharkey SW, Windenburg DC, Lesser JR, et al. Natural history and expansive clinical profile of stress (tako-tsubo) car- diomyopathy. J Am Coll Cardiol 2010;55: 333-41.

10. Elesber AA, Prasad A, Lennon RJ Wright RS, Lerman A, Rihal CS. Four-year recurrence rate and prognosis of the apical ballooning syndrome. J Am Coll Cardiol 2007;50:448-52.

11. Wittstein IS, Thiemann DR, Lima JA et al. Neurohumoral features of myocardial stunning due to sudden emotional stress. N Engl J Med 2005;352:539-48.

12. Kyuma M, Tsuchihashi K, Shinshi Y, et al. Effect of intravenous propranolol on left ventricular apical ballooning without coronary artery stenosis (ampulla cardiomyopathy): three cases. Circ J 2002;66: 1181-4.

13. Prasad A, Lerman A, Rihal CS. Apical ballooning syndrome (Tako-Tsubo or stress cardiomyopathy): a mimic of acute myocardial infarction. Am Heart J 2008;155: 408-17.

14. Thygesen K, Alpert JS, Jaffe AS, et al Third universal definition of myocardial infarction. Circulation 2012;126:2020-35. 15. Diagnostic and statistical manual of mental disorders. 4th ed. Arlington, VA American Psychiatric Association, 2000. 16. Schneider B, Athanasiadis A, Stöllberger $\mathrm{C}$, et al. Gender differences in the manifestation of tako-tsubo cardiomyopathy. Int J Cardiol 2013;166:584-8.

17. Aizawa K, Suzuki T. Takotsubo cardiomyopathy: Japanese perspective. Heart Fail Clin 2013;9:243-7.

18. Brandspiegel HZ, Marinchak RA, Rials SJ, Kowey PR. A broken heart. Circulation 1998;98:1349.

19. Eitel I, von Knobelsdorff-Brenkenhoff F, Bernhardt P, et al. Clinical characteristics and cardiovascular magnetic resonance findings in stress (takotsubo) cardiomyopathy. JAMA 2011;306:277-86. 20. Lee VH, Connolly HM, Fulgham JR,
Manno EM, Brown RD Jr, Wijdicks EF. Tako-tsubo cardiomyopathy in aneurysmal subarachnoid hemorrhage: an underappreciated ventricular dysfunction. J Neurosurg 2006;105:264-70.

21. Le Ven F, Pennec PY, Timsit S, Blanc JJ. Takotsubo syndrome associated with seizures: an underestimated cause of sudden death in epilepsy? Int J Cardiol 2011; 146:475-9.

22. Sharp RP, Welch EB. Takotsubo cardiomyopathy as a complication of electroconvulsive therapy. Ann Pharmacother 2011;45:1559-65.

23. Riera M, Llompart-Pou JA, Carrillo A, Blanco C. Head injury and inverted Takotsubo cardiomyopathy. J Trauma 2010; 68(1):E13-E15.

24. Yoshimura S, Toyoda K, Ohara T, et al. Takotsubo cardiomyopathy in acute ischemic stroke. Ann Neurol 2008;64:547-54.

25. Summers MR, Lennon RJ, Prasad A. Pre-morbid psychiatric and cardiovascular diseases in apical ballooning syndrome (tako-tsubo/stress-induced cardiomyopathy): potential pre-disposing factors? J Am Coll Cardiol 2010;55:700-1.

26. Galiuto L, De Caterina AR, Porfidia A, et al. Reversible coronary microvascular dysfunction: a common pathogenetic mechanism in Apical Ballooning or TakoTsubo Syndrome. Eur Heart J 2010;31: 1319-27.

27. Cheung RT, Hachinski V. The insula and cerebrogenic sudden death. Arch Neurol 2000;57:1685-8.

28. Bybee KA, Prasad A. Stress-related cardiomyopathy syndromes. Circulation 2008;118:397-409.

29. Parodi G, Citro R, Bellandi B, et al. Tako-tsubo cardiomyopathy and coronary artery disease: a possible association. Coron Artery Dis 2013;24:527-33.

Copyright (C) 2015 Massachusetts Medical Society. 